\title{
CHANGING LEARNING ENVIRONMENT THROUGH TECHNOLOGY
}

\author{
Florin Mihai ${ }^{1}$ \\ Andrei Stanciu ${ }^{2}$ \\ Ofelia Aleca ${ }^{3}$
}

\begin{abstract}
Evolution of E-learning phenomenon exceeded all expectations in recent years. As a result of development of IT\&C technologies and, on the other hand, due to support decision-makers at European level, the assimilation of virtual learning platforms in schools and universities has become a normal phenomenon.

The E-learning 2.0 concept seeks to revolutionize traditional learning methods and requires major changes in the perception of the educational process of teaching and learning.

This article tries to create an overview of the main development directions and emphasizes the impact that computer-assisted instruction technologies have on teaching and learning methods, with a direct connection to distance learning and blended learning concepts. Also, we have tried to open a perspective on the concept of e-Assessment and related technologies
\end{abstract}

Key words: e-learning 2.0, computer based training, e-assessment, blended learning, distance learning

JEL codes: D8, P28

\section{Introduction}

The widespread use of IT\&C technologies in education has already become a phenomenon with a large development in the first decade of the 3rd millennium.

Based on E-learning concept are described all the learning and teachings methods assisted by It\&C systems in order to transfer knowledge and skills acquisition.

Due to continuous development, and as a result of accelerated evolution in the software applications designed for educational domain, definitions are constantly changing and new concepts are emerging (some of the new emerging concepts are synonymous with E-learning: CBT (Computer Based Training), IBT (Internet Based Training) or WBT (Web based Training).

The involvement of many big companies on the e-learning technology market has had a major impact and contributed significantly to the development.

According to the UE Commission reports, since 2000, the global turnover on the market of software applications designed for educational domain was estimated around 48 millions dollars.

Nowadays the advantages of using IT technologies in teaching and learning are widely appreciated especially for:

- Flexibility of study which is not restricted by a fixed schedule and allows widely access considering that the use of virtual learning platforms no longer requires expensive technology.

- Broad access for students / pupils to information and the opportunity to be trained by the best teachers, without any geographical or temporal barriers

\footnotetext{
1 The Bucharest Academy of Economic Studies, Faculty of Accounting and Management Information Systems, Romania, e-mail:fmihai@ase.ro

2 The Bucharest Academy of Economic Studies, Faculty of Accounting and Management Information Systems, Romania, e-mail: andreis@mailcig.ase.ro

3 The Bucharest Academy of Economic Studies, Faculty of Accounting and Management Information Systems, Romania, e-mail:ofemasec@mailcig.ase.ro
} 
- The development of skills in a modern, collaborative environment which provides simultaneous assimilation of knowledge needed in the field of information technology and communications

According to a report published by the Sloan Foundation in 2006 approximately 3.5 millions students were using various forms of online education in higher education institutions in the United States. The same report forecasts an annual growth of 12-14 percent of users for virtual learning platforms. Allen and Seamen [2] (2009) consider that around a quarter of American students benefited of fully online courses during the 2008 academic year and, in a published report by Ambient Insight Research [3], is estimated that, in 2009, 44\% of American students received support for training in online format. The same report forecasted a growth to 81 percent until 2014. A very interesting research report published in January 2010 by the same authors (Allen and Seamen, 2010) explores the impact of economic crisis on submissions from programs of study in U.S. universities. Perhaps contrary to expectations, interest in education has increased during this period. The fact we think deserves to be emphasized is a greater interest for the online studies than for classical "face to face" programs.

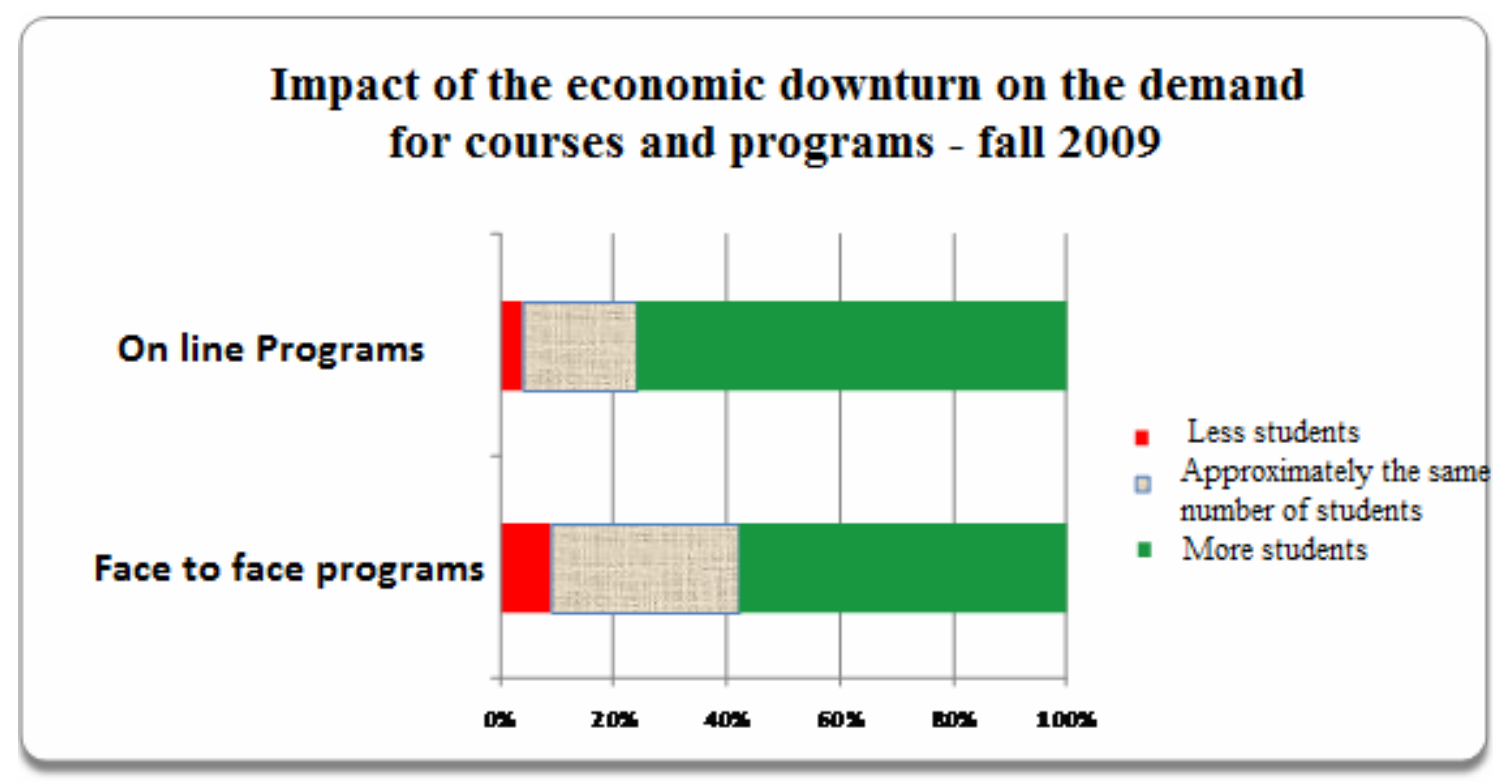

Figure no. 1. Impact of the economic downturn on the demand for courses and programs - fall 2009

In Europe, beginning with the eEurope initiative launched from June 2002 in order to speed up Europe's transition to a knowledge-based economy, the issue of using digital technologies in educational processes has made the objective for several initiatives aiming to improve the scholar programs, to foster the development of educational resources on Internet and to provide support for the e-Learning platforms.

In Romania, a very recent study conducted by SIVECO Company [18] reveals that 58 percents of Romanian universities are using E-learning platforms.

The success of virtual learning environments in the recent period is confirmed by the penetration of IT technologies in the field of doctoral training (online doctoral programs), through many project developed in leading research universities.

\section{Research methodology}

Research conducted for this paper is being focused on highlighting the fundamental impact that new computer-assisted technologies have on teaching and learning methods. Based on an extensive literature review, research opens perspectives on the concept of e-assessment and related 
development technologies. The methodologies used in this article are assumed to gather information focused on technology developments in computer-assisted instruction.

\section{European Initiatives}

Following the booming development of communication technologies based on Internet technologies, the first initiative of the European Union policy for e-learning was materialized in 1999 through the eEurope initiative. However, the crucial role assigned to e-Learning systems in order to speed up efforts to harmonize the educational technologies is highlighted even on the web portal of the European Union (http://ec.europa.eu/). In fact, eEurope initiative was the starting point for several initiatives and action plans arising thereafter.

The eEurope program has established a few key objectives:

- Guiding every citizen and business conducted by organizations in the digital age;

- Promoting youth digital literacy in the education process in schools;

- Assuring cheaper Internet access;

- Fostering e-Commerce technologies;

- Supporting e-Health and e-Governance development.

Designing Tomorrow Education report presented to the European Council in Brussels on 28th March 2001 mentioned the importance of adopting new educational technologies (including elearning) by the candidate countries to EU membership. Beginning from the idea that economic and social future of Europe is currently building in the classroom is obvious that students need good professional training and a thorough preparation in digital technologies as future members of a society based on knowledge.

In 2002, the European Council held in Seville, adopted the eEurope 2005 action plan to accelerate the transition of Europe towards a knowledge-based economy, and the subject of using digital technologies in educational processes has made several initiatives aiming at adapting the school curricula to use communicative technologies and to develop educational resources on the Internet and E-Learning platforms.

This action plan had the following key objectives for e-learning:

- Providing access to the Internet for all schools and universities by 2005;

- Secure on-line access for students and researchers on universities' sites;

- European Commission's involvement through supporting the research of e-learning platforms and modern networks;

- Support provided by member states for various training activities for adults in order to give them the necessary skills to work in a knowledge society.

This initiative was followed by another in 2005 called "i2010 - A European Information Society for growth and employment" which attempted to boost knowledge and innovation activities for economic growth and creating new jobs.

In 2009, with the adoption of the ET2020 strategic framework for European cooperation in education and professional training, cooperation between EU states took on new meanings in terms of e-Learning. It was stated that high-quality education at all levels, involving support provided by information and communication technology is essential for Europe's success. The strategic objectives proposed by the European initiative aims to:

- Promoting the access to new knowledge through long life learning concept;

- Promoting the mobility of students;

- Improving quality and efficiency of education and training;

- Promoting equity and social cohesion;

- More creativity and innovation, including entrepreneurship innovation at all levels of education and training;

- Adoption of ICT at all levels of education. 


\section{Technological and conceptual developments: Elearning 2.0}

The former e-learning systems based on the concepts of Computer-Based Learning / Training were largely mainly designed to assist the teacher in classical teaching methods with elearning tools designed to facilitate knowledge transfer. The evolution of technologies and methods of learning has led the e-learning systems to the current concept of Computer Supported Collaborative Learning (CSCL), which encourages collaborative development of knowledge.

E-Learning 2.0 is the established term for platforms such CSLC (Computer-supported collaborative learning) e-learning which are based on web portals benefiting from Web 2.0 technologies. E-learning 2.0 concepts suggest the imminent transformation beyond the classic perception of online education which had presumed that e-learning tools were only meant for the distribution of educational packages to students using the Internet. In scientific papers, this tendency to transform e-learning process and to convergence with social networking is referred by some authors as Long Tail Learning (Karrer, T 2008).

E-Learning 2.0, unlike systems not based on CSCL, involves the accumulation of knowledge as a social phenomenon which can be socially constructed and consider effective learning through conversations and interactions of various types in the virtual environment.

In recent years a massive increase in the number of virtual classes (delivered live online presentations) was recorded in high education. Complementary to virtual classes, accessing social networks as learning environments has become a basic component of E-learning 2.0 concepts.

The main role of social networks is to coagulate virtual learning communities within the scope of discussions on topics such scientific subjects, virtual experiments or other various themes as exams preparation. A major impact in promoting these activities focused around the concept of "social networking" is provided nowadays by the development of client applications for mobile devices which enhance their accessibility.

Moreover, the development of technologies needed to implement e-learning software on the latest generation telephone devices and other mobile devices has led to the shaping of new concepts such as mobile-learning or, in learning foreign languages, Mobile Assisted Language Learning (MALL).

Through implementing new modern technologies, e-learning 2.0 is aiming to remove one of the common limits of online learning programs: the difficulty of creating a positive learning environment from a socio-cultural perspective.

\section{Impact of e-learning on learning methods}

Using Internet technology within learning has the effect of improving literacy, improving access to information and training, reducing the cost of education (Bates, 1997).

Hybrid models of education are very popular and are growing rapidly in response to a higher demand for making learning process more effective. Studying the ways of learning in terms of technologies used, in the field of eLearning education will fit all situations in which significant use of ICT resources exists.

In a narrow sense, eLearning is a type of distance education, as a planned teaching-learning experience organized by an institution that provides the material environment in a sequential and logical order to be assimilated by students in their own manner.

Long Life Learning concept involves continuous training that includes initial training, professional training and continuing education. Knapper and Cropley (2000) assume that long-term learning (Long Life Learning) implies planning by participants for their own manner of learning, depending on personal availability, which leads to their stimulation to learn. "Lifelong learning is no longer just one aspect of education and training; it must become the guiding principle for participation and provision across the full continuum of learning contexts“(EC, 2000, p. 3). Longterm learning strategy should also include the years of school (M Demirel, 2009).

Elearning technology provides flexibility for the development of learning support 
throughout the entire life, regardless of the period and manner of preparation and availability of the trainee. Life long learning can be planned depending on the preparation stage of training of each individual student, through various methods, including the face to face training and distance learning method. Being directly connected with the use of ICTs in education, distance learning is a part of the Long-Term Learning (Köse, 2010).

Distance learning refers to learning situation which implies that the trainer and the student are not in the same physical location or may be located in the same location but not at the same time. Unlike e-learning, traditional face to face training provides a direct social environment for the students.

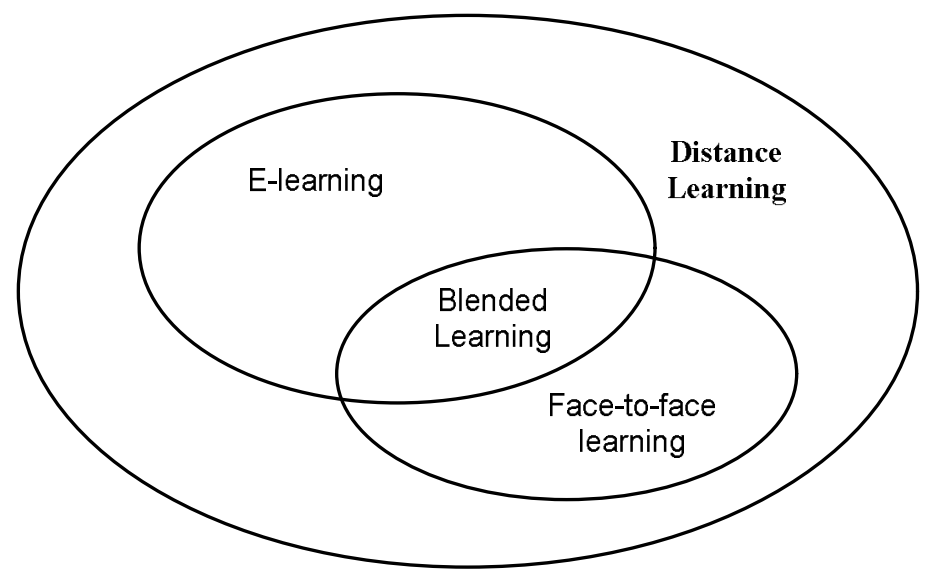

Figure no. 1 - Elearning influences in shaping conceps as distance learning and blended learning (Karadeniz, 2009)

Karadeniz (2009) considers blended learning (b-learning) as a combination of e-learning and face-to-face learning that can be encountered in distance learning environment.

Learning Blended learning concept involves mixing different learning and training techniques. Harriman (2004) asumes that learning Blended Learning combines face to face with online learning in order to provide the most effective learning experiences.

Procter (2003) defines blended learning as a mix of different techniques, technologies, and educational models that meet students' needs.

Optimizing outcomes and costs is, according to Singh and Reed (2001), the reason why the blend of different learning methods and models is more often used.

Valiathan (2002) takes in account that various training methods such as collaboration software, knowledge management and Web-Based Courses practices should be used in the training process.

Singh (2003) sees blended learning as a mixture of multiple media applications able to complement each other in order to provide a basis for learning.

A model for proper blended learning using Web 2.0 technologies was provided by Kose (2010): 


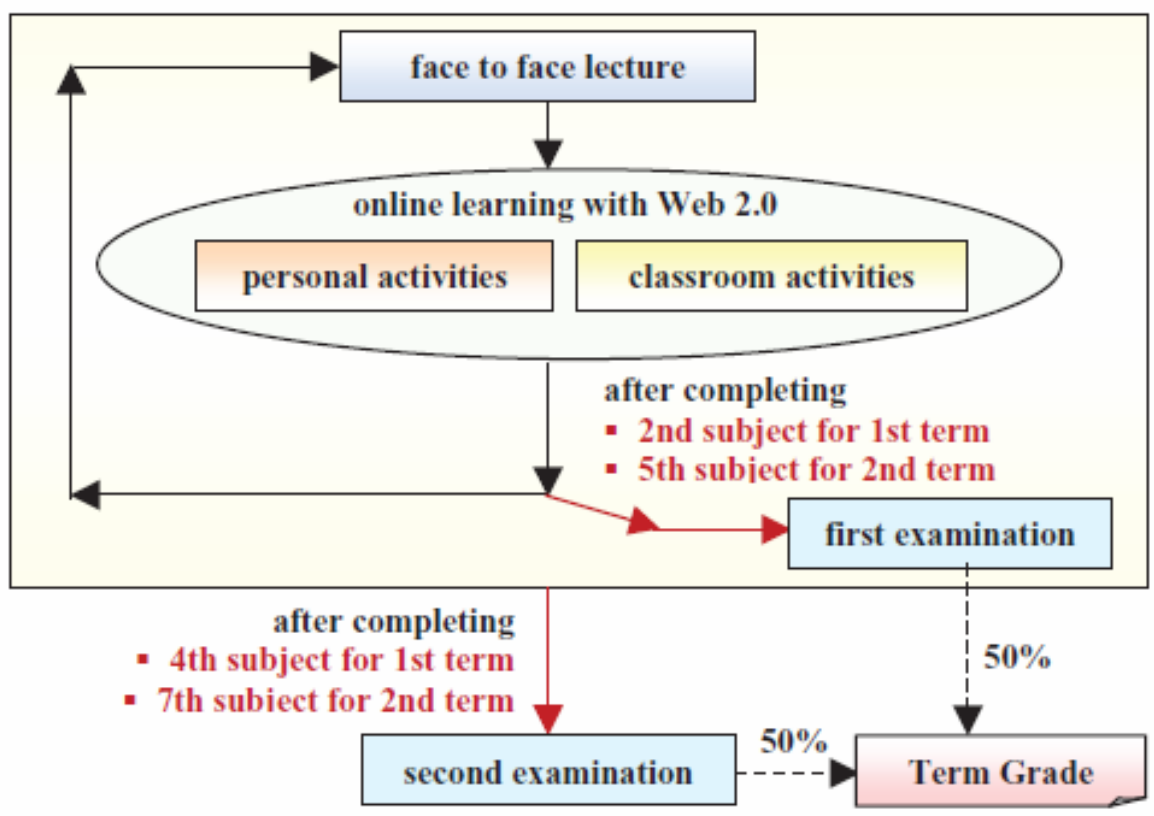

Figure no. 2 - Blended Learning Model (Sursa Köse, 2010)

Changing perceptions about learning process and widespread use of virtual environments are inevitably leading to a new approach of the research in the assessment of knowledge practices and technologies.

The designers of e-learning platforms have formerly used the term Computer-Aided Assessment tools in order to classify application designed for knowledge evaluation activities.

Following the increasing demands for software applications in this category, the e-assesement term became popular among educational communities. Dedicated e-assesement applications, providing tests with multiple answers but also complex simulations based on interactive multimedia technology have started to become integrated into e-learning systems.

Advantages of using ICT technologies to assess student performance include lower administrative costs, increased adaptation to individual characteristics of students and teachers and less work in the stage of examination.

The problems which arise are concerning the efficiency of assessments using the computer and the relationship between the assessment process and student behavior, especially the perception of students regarding the use of ICT technologies. The most often arised question is concerning about students' capability to understand and adapt test tasks in a new, less conventional, examination environment. There are also mentioned difficulties regarding the conversion and implementation of some types of clasic tests in on-line versions.

The examination stages which take advantage of using ICT technologies are records management and test results analyze. Current trends in e-assessement systems design regard the improvement of methods for identifying gaps in students' knowledge, allowing transmission of feedback to the students and guiding the exercises in order to eliminate the weaknesses. Based on these statements we can conclude that the emphasis should be on formative assessment and feedback obtained through the use of computer assisted evaluation.

There are several initiatives at European level in the field e-Assessment technologies. Among them, we could mention the British government initiative since 2005 when a document entitled "Towards an e-learning strategy" was published. The initiative regards several structural and pedagogical proposals that constitute a model for higher education. Recommendations regarding computer-assisted examinations are converging to extend e-assessement beyond simple use of multiple choice tests and to develop more complex assessment strategies in order to provide more useful feedback to students during the learning. 
Recently, in Sweden, Distum (Swidish Distance Education Authority) has undertaken a project funded by the European Commission - "Internet based Assessment in distance education" which concerned the implementation of ICT-based assessment of students, the advantages and disadvantages, and determining the assessments'impact. One of the project conclusions found that students are more motivated when learning activities involves use of new technologies.

\section{The standardization process in elearning}

A comprehensive approach to the trends within dedicated e-learning technologies could not ignore the initiatives concerning the development of standards for e-learning systems.

Although e-learning technology domain is relatively young, like any dynamic segment of IT\& C technologies has quickly required the need standardization.

The main objectives of standardization in the field of elearning aim to ensure the reuse of educational resources and the compatibility between educational platforms.

There are four categories of standards, according to Horton - E-Learning Tools and Technologies (http://www.horton.com):

- Packaging Standards - allowing the import and assembly of courses from individual modules or learning objects (LOS);

- Communication Standards - enabling the systems to provide lessons and to manage homeworks and tests;

- Metadata Standards - specify the description of modules in order to create catalogs of educational content;

- Quality Standards - establish criteria for quality and accessibility.

Nowadays, the most refered standards are ADL (Advanced Distributed Learning) and IEEE (Institute of Electrical and Electronic Engineers Learning Technology Standards Committee).

I. Advanced Distributed Learning ( $A D L)$

ADL is a U.S. government-funded organization that has as purpose the research and development of specifications to encourage the development and popularization of e-learning.

The best known and widely accepted is SCORM project (Shareable Content Object Reference Model) that defines the nanner of communication between the client and the learning management system, and how content can be packed in a zipped file transferable. characteristics;

- According to SCORM standard, educational content should have the following

- Accessibility, content must be accessible when needed;

- Interoperability, content must be accessed regardless of the e-learning platform or the operating system used;

- Reuse, content must be independent of learning context, being used by different users; are changed.

- Durability, content must not require changes in order to operate when software systems

II. Institute for Electrical and Electronic Engineers Learning Technology Standards Committee (IEEE LTSC)

IEEE is an international organization which develops technical standards and recommendations on hardware and communications systems.

Standards proposed by the IEEE are widely recognized and internationally adopted. The bestknown initiative is the specification for Learning Object Metadata (LOM), which defines groups and educational elements that describe a learning object. 


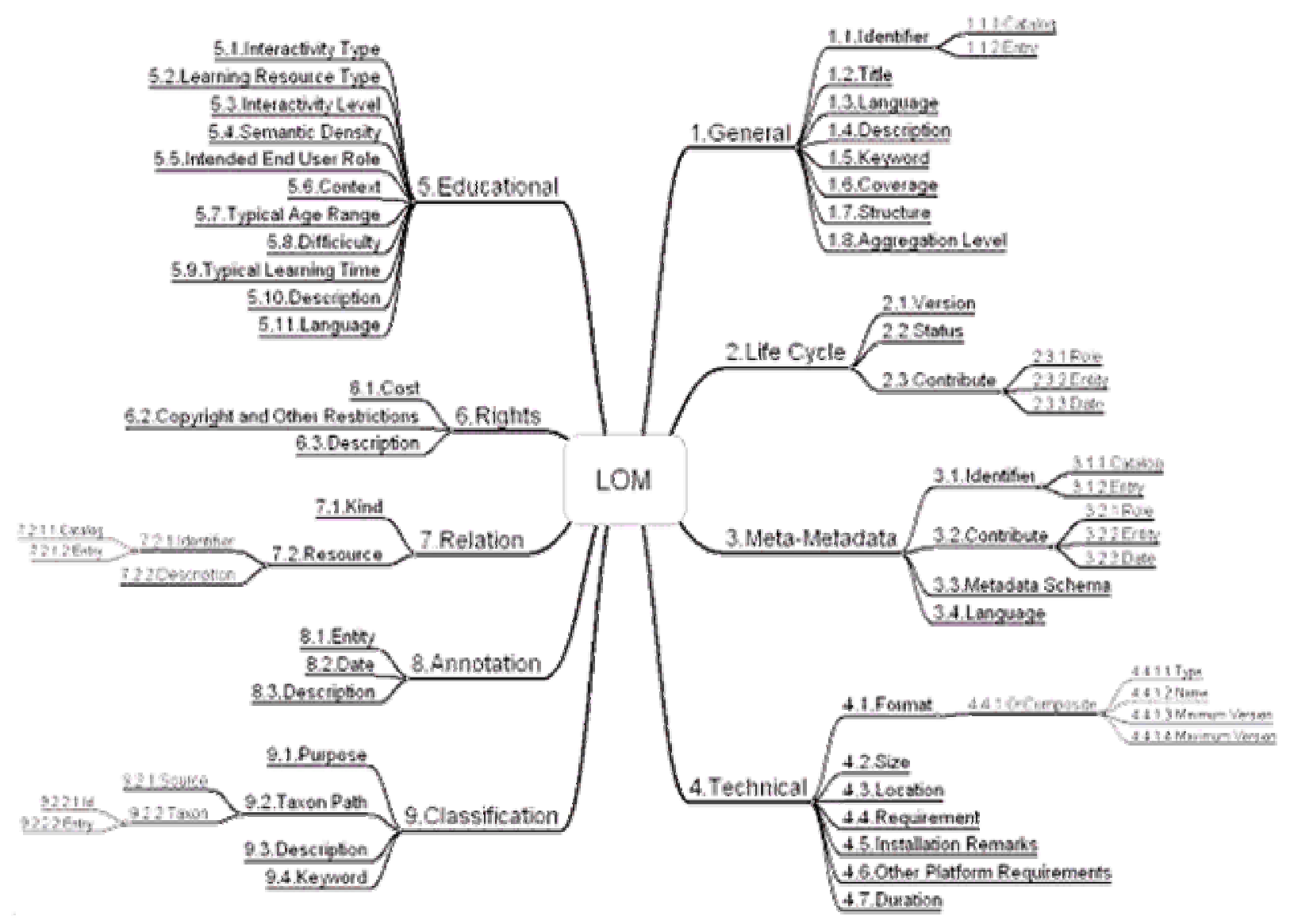

Figure no. 3 - The elements and structure of the LOM conceptual data schema (http://www.imsglobal.org)

\section{Conclusions}

Although a relatively young phenomenon, strongly supported by the dynamic trend of progress in IT\&C technologies, e-learning tends to become an important factor in shaping educational processes.

In higher education, recent researches in university highlighted an increasing trend for higher rates on interest in online technology-based courses from classic "face to face" courses.

Moreover, the success of virtual learning environments is confirmed by the implementation of technologies in all spheres of education, starting with e-twinning projects which are involving schools to doctoral programs in prestigious universities.

The main advantage of e-learning is the adaptive behaviour of the developers who have provent to beare able to keep the pace with the changes and take advantage of the innovation in ITC sector.

A good example is the very quick adoption of Web 2.0 technology which has led to a reinnovation of the concepts and started the transition to a new era, the era of e-learning 2.0 systems.

The key of success consist not only in a prompt response regarding the evolution of support technologies, but also in remodelling educational processes through developing new concepts as Computer Supported Collaborative Learning (CSCL) which encourages collaborative development of knowledge.

It can be concluded that e-learning platforms have radically changed student and teacher's role in learning and promoted the concept of social learning by using social software tools (such as 
blogs, online encyclopaedias and virtual worlds).

Changing the global perspective regarding the manner of learning and the widespread use of virtual environments have inevitably led to new directions in educational research, some of them aiming to improve the assessment of knowledge through new technologies.

Modern systems, especially designed for e-assessment, provide tools for scheduled test of knowledge able to discover and correct weak points or lacunas in students training.

Not at last, the flexibility of elearning systems provides support for developing long life learning programs, independent of the availability or the type of training of each person, contributing to the development of new concepts which provide effectiveness to learning processes. One of these concepts is know as Blended Learning and suppose a mix of "face to face" classical learning with on-line learning sessions.

\section{References}

1. Allen I. E. and Seaman J., 2008. Staying the Course: Online Education in the United States, 2008 Needham MA: Sloan Consortium

2. Ambient Insight Research, 2009. US Self-paced e-Learning Market Monroe WA: Ambient Insight Research

3. Allen I. E. and Seaman J., 2010. Learning on Demand: Online Education in the United States, 2010 Babson Survey Research Group

4. Hebert D. G., 2007. Five Challenges and Solutions in Online Music Teacher Education.

5. Karrer T, 2008. Corporate Long Tail Learning and Attention Crisis Elearningtech.blogspot.com

6. Harriman G., 2004a. What is blended learning?, E-Learning Resources, Retrieved October 13, 2009, from http://www.grayharriman.com/blended_learning.htm

7. Harriman G., 2004b. What is Distance Learning?, E-Learning Resources, Retrieved October 13, 2009, from http://www.grayharriman.com/blended_learning.htm

8. Köse U., 2010. A blended learningnext term model supported with Web 2.0 technologies, Procedia - Social and Behavioral Sciences, Volume 2, Issue 2, Pages 2794-2802

9. Procter C., 2003. Blended learning in practice. The Education in a Changing Environment Conference. Salford: University of Salford.

10. Singh H., Reed C., 2001. A White Paper: Achieving Success with Blended Learning. Los Angeles: Centra Software

11. Valiathan P., 2002. Blended learning models. Learning Circuits, Retrieved October 17, 2009 from http//www.learningcircuits.org/2002/aug2002/valiathan.html

12. Singh H., 2003. Building effective blended learning programs. Educational Technology, 43(6), 51-54.

13. Karadeniz Ş, 2009. Flexible design for the future of distance learning, Procedia Social and Behavioral Sciences 1, 2009 358-363

14. EC, 2000. Memorandum on Lifelong Learning. Commission of European Communities, Brussels.

15. Knapper C., Cropley A.J., 2000. Lifelong learning in higher education. London: Kogan Page.

16. Demirel M 2009. Lifelong learning and schools in the twenty-first century Original Research Article

17. Procedia - Social and Behavioral Sciences, Volume 1, Issue 1, Pages 1709-1716

18. Crahmaliuc A, SIVECO Romania, 58\% dintre universitatile din Romania utilizeaza solutii de eLearning, from http://www.elearning.ro 